\title{
RUANG BELAJAR MASA DEPAN : SEBUAH TIPOLOGI BARU BANGUNAN PENDIDIKAN
}

\author{
Sebastian Michael Kwee ${ }^{1)}$, Maria Veronica Gandha ${ }^{2)}$ \\ 1)Program Studi S1 Arsitektur, Fakultas Teknik, Universitas Tarumanagara, michaelkwee777@gmail.com \\ 2) Program Studi S1 Arsitektur, Fakultas Teknik, Universitas Tarumanagara, mariag@ft.untar.ac.id
}

\begin{abstract}
Abstrak
Sekolah adalah suatu lembaga pendidikan yang dirancang khusus untuk mendidik siswa/ murid dalam pengawasan pengajar atau guru. Fasilitas sekolah selalu berkembang mengikuti perkembangan jaman dikarenakan adanya perkembangan teknologi serta perubahan perilaku dari penggunanya. Indonesia masih mengalami masalah dalam kondisi ruang kelas yang buruk sekitar $65 \%$ kondisi ruang kelas di Indonesia masih mengalami kerusakan, khususnya dalam taraf Sekolah Dasar. Sekolah Dasar di daerah Jakarta pada umumnya masih menggunakan sistem konvensional dimana guru masih mengajar secara satu arah, dan ruang kelas yang menggunakan sistem meja berderet, serta kurangnya ruang- ruang komunal untuk cara belajar yang berbeda. Hal ini menandakan sudah tidak ada relevansi antara sekolah dengan penggunanya, dimana milenial sudah mulai mendominasi dunia pendidikan menjadi pengajar dengan metode yang lebih inovatif, serta murid- murid yang sudah memiliki cara pembelajaran yang berbeda, terutama dengana adanya bentuan teknologi dan tren yang lebih variatif. Program yang diusulkan, yaitu ruang belajar masa depan adalah fasilitas belajar yang sesuai dengan konteks keperluan warga Jakarta dimana generasi milenial dapat menggunakan metode mengajar yang lebih variatif dan fleksibel, yang menyebabkan generasi $Z$ serta seterusnya dapat belajar dengan gaya mereka sendiri. Serta adanya program pendukung seperti ruang kerja bersama, fasilitas olahraga yang dapat mendukung kegiatan milenial yang ada di daerah Cakung, Jakarta Timur dan sekitarnya.
\end{abstract}

Kata kunci: relevansi; anak; belajar; millennial; ruang

\begin{abstract}
School is an institution for educating children in the supervisor of their teachers. School facilities are always evolving to follow the times due to technological developments and changes in behavior of users. Indonesia is still experiencing problems in poor classroom conditions around $65 \%$ of the condition of classrooms in Indonesia is still experiencing damage, especially in the Elementary School level. Primary schools in the Jakarta area generally still use a conventional system where teachers are still teaching in one direction, and classrooms that use desk systems are lined up, and lack communal spaces for different ways of learning. This indicates that there is no relevance between the school and its users, where millennials have begun to dominate the world of education to become teachers with more innovative methods, and students who already have different learning methods, especially with the availability of technology and more varied trends. The proposed program, which is the future learning space, is a learning facility that fits the context of the needs of Jakarta residents, where the millennial generation can use a more varied and flexible teaching method, which causes $Z$ generation onwards to learn in their own style. As well as supporting programs such as shared work spaces, sports facilities that can support millennial activities in the Cakung area, East Jakarta and surrounding areas.
\end{abstract}

Keywords: relevance; child; learn; millennial; space

\section{PENDAHULUAN}

Pada era milenial, profesi guru telah berubah dan mengalami perkembangan yang pesat, sehingga ada perubahan paradigma Sekolah di abad ke 21. Indonesia masih mengalami isu tentang keburukan kondisi ruang kelas, khususnya di taraf Sekolah Dasar. 
Tabel 1. Kondisi Ruang Kelas di Indonesia

\begin{tabular}{llllll}
\hline Ruang Kelas & 930,825 & 86,82 & 141,311 & 13,18 & $1,072,136$ \\
\hline Menurut Kondisi & & & & & \\
\hline Baik & 221,104 & 78,10 & 62,005 & 21,90 & 283,109 \\
\hline Rusak Ringan & 535,765 & 89,26 & 64,442 & 10,74 & 600,207 \\
\hline Rusak Sedang & 75,558 & 92,59 & 6,043 & 7,41 & 81,601 \\
\hline Rusak Berat & 58,342 & 92,42 & 4,786 & 7,58 & 63,128 \\
\hline Rusak Total & 40,056 & 90,85 & 4,035 & 9,15 & 44,091 \\
\hline
\end{tabular}

Sumber: Kemendikbud, 2018

Data menunjukkan bahwa murid di Sekolah Dasar merupakan pelajar dengan populasi yang terbanyak, yakni sejumlah 25,486,506 murid hanya memiliki 283,109 ruang kelas dengan kondisi baik, sedangkan 789,027 lainnya mengalami kerusakan dari ringan hingga rusak total.

Visi dari proyek ini adalah Menjadi fasilitas belajar yang berkembang berdasarkan kesejamanan serta dapat turut membangun dan menginspirasi perkembangan pendidikan yang ada di Jakarta untuk generasi sebelum ataupun yang akan datang.

Ada beberapa tujuan atau dampak positif yang akan diberikan oleh proyek ini terhadap kota, antara lain :

- Ikut melaksanakan Sustainable Development Goals yang bermanfaat bagi lingkungan

- Memberi perspektif baru tentang arsitektur sebuah tempat belajar

- Ikut menyelesaikan masalah terkait dengan kondisi ruang kelas yang buruk

- Memberi lapangan pekerjaan baru

Ruang belajar masa depan memiliki konsep ruang yang varfiatif dan fleksibel, hal ini dibentuk agar sebuah sekolah dapat terus beradaptasi dengan adanya perkembangan teknologi maupun pergantian metode belajar. Aspek alami seperti pencahayaan dan pengudaraan ikut dimasukkan kedalam bangunan secara optimal untuk menghemat energi.

\section{KAJIAN LITERATUR}

Sekolah adalah suatu lembaga pendidikan yang dirancang khusus untuk mendidik siswa/ murid dalam pengawasan pengajar atau guru, sedangkan di era milenial ini sumber pengetahuan sudah lebih mudah untuk diakses salah satunya dengan teknologi, sehingga peran seorang guru mulai beralih, bukan menjadi sumber pengetahuan melainkan menjadi pemandu. Generasi muda seperti generasi milenial dan seterusnya sudah sangat tergantung terhadap teknologi, sehingga cara belajar dan mengajar dari generasi ini berbeda dari generasi- generasi sebelumnya.

Sekolah Dasar pertama di Indonesia yang bisa digunakan untuk pribumi Indonesia adalah HIS yang berdiri pada tahun 1914. Terlihat adanya perubahan arsitektur dari masa ke masa, antara lain menjadi bangunan bertingkat sehingga kapasitas yang ditampung menjadi lebih banyak, gaya arsitektur yang lebih modern, dan fasilitas lebih bervariatif seperti adanya laboratorium atau workshop yang mengikuti perkembangan jaman.

Perkembangan ruang kelas tidak terlalu banyak terjadi, karena kebanyakan Sekolah Dasar yang ada sudah terbangun di beberapa generasi sebelumnya, sehingga generasi yang sekarang menempati terpaksa beradaptasi dengan kondisi sekolah yang ada. Kurikulum telah mengalami pembaruan di tahun 2013, yang menggunakan metode pembelajaran lebih inovatif sehingga murid menjadi lebih antusias. Maka tipe dari ruang kelas perlu diubah demi kenyamanan dan keleluasaan pada saat dinamika tersebut, karena bentuk ruang kelas seperti ini memang sudah tidak cocok untuk kurikulum dan kriteria sekolah di abad ke 21 . 


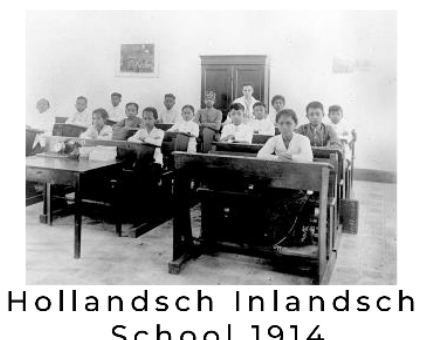

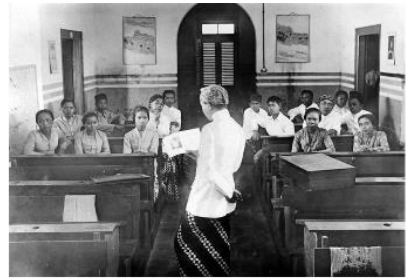

Taman Siswa 1922

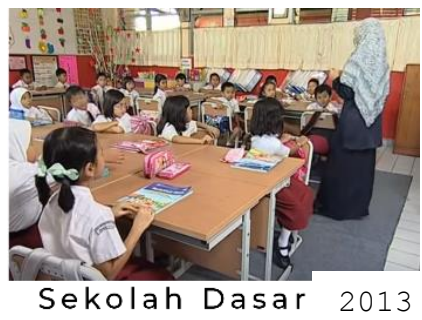

School 1914

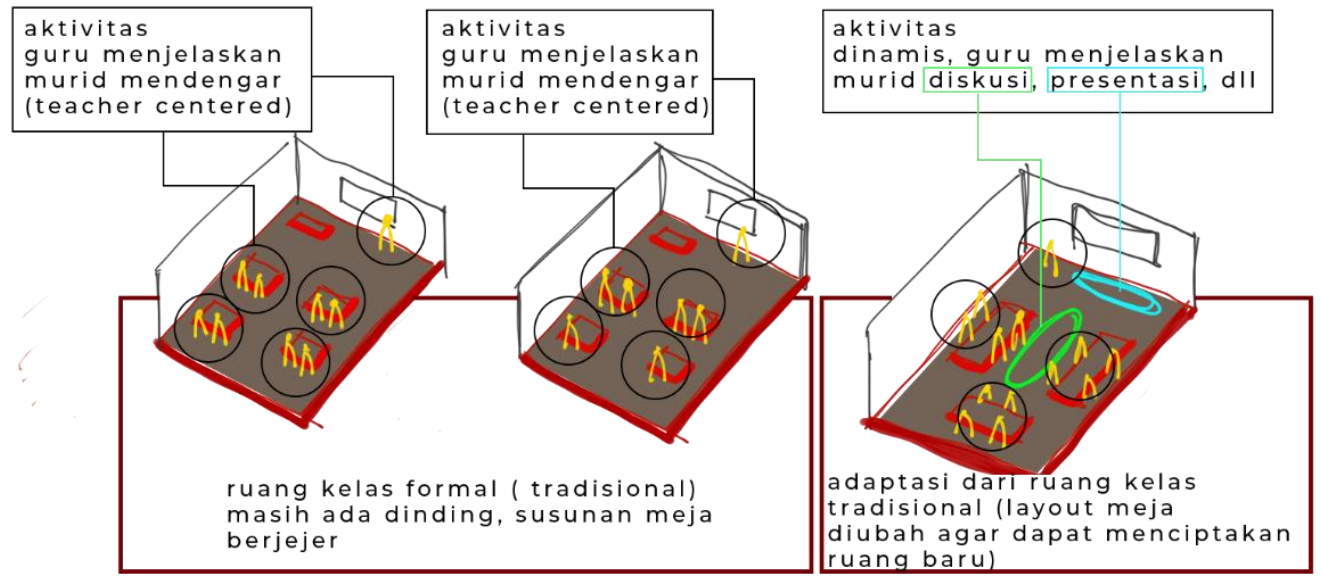

Gambar 1. Perubahan Ruang Kelas

Sumber: Penulis, 2019

Diagram diatas menunjukkan perbedaan yang cukup banyak antara sekolah di tahun 1914, dan sekolah dasar di tahun 2013 terlihat dari perbedaan tata meja, meskipun kondisi arsitektur sekolah hampir sama, tetapi sistem belajarnya sudah jauh berbeda. Oleh karena itu fasilitas sekolah harus lebih dioptimalkan lagi sehingga murid semakin antusias dalam belajar. Menurut Mundy, 2012; paradigma sekolah pada abad ke 21 akan berubah dari abad sebelumnya, dikarenakan adanya kemajuan edukasi dari sisi teknologi dan perilaku.

Tabel 2. Perubahan Paradigma

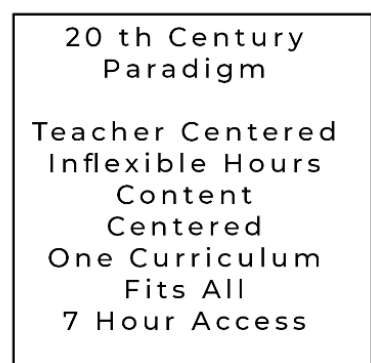

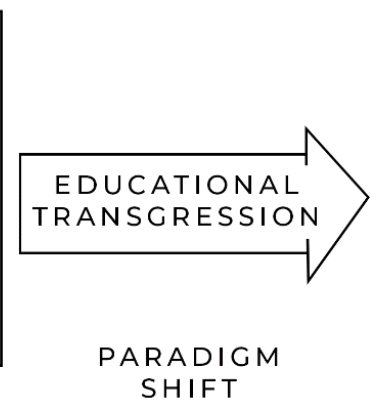

Sumber : Mundy, 2012

Perubahan paradigma terjadi karena adanya perkembangan teknologi yang akan mempengaruhi kebiasaan dari generasi selanjutnya. Tuntutan guru ( sisi Millennial) yang diarahkan untuk mengajar dalam cara yang lebih kreatif dan inovatif. Menurut Rosan Bosch beliau sudah meneliti tentang cara belajar bagi generasi muda yang sesuai dengan abad ke 21, antara lain ada metode Mountain Top, metode Cave, metode Campfire, metode Watering Hole, metode Hands On, dan metode Movement. Metode ini menerapkan desain ruang belajar yang berbeda- beda sesuai dengan tujuan dari masing- masing metode belajar. 


\section{METODE}

Metode yang dipilih dalam perancangan ini salah satunya adalah metode Pattern Language oleh Christopher Alexander. Dalam metode ini, Christopher Alexander mengamati pola dari perilaku manusia sehingga dapat diterapkan dalam sebuah perancangan, mulai dari arsitektur bangunan sampai perancangan sebuah kota. Pola/ pattern yang diamati adalah kegiatan yang terulang-ulang sehingga menimbulkan sebuah rutinitas yang dapat dimasukkan dalam aspek desain. Pola yang dipelajari akan sesuai dengan urutan dimulai dari yang paling besar, yaitu regional dan kota, lalu menuju ke lingkungan, kumpulan bangunan, lalu ke bangunan, ruangan dan berakhir di detil konstruksi (Alexander, 1977).

Metode ini dipakai untuk mempelajari cara milenial mengajar generasi yang lebih muda, sehingga program yang ditentukan akan mendukung proses belajar mengajar. Setelah melakukan pengamatan dari masing- masing cara belajar dan mengajar dari generasi milenial dan generasi yang lebih muda, maka dibutuhkan ruang- ruang yang lebih fleksibel dan desain ruang yang spesifik agar dapat digunakan untuk aktivitas tertentu. Tipe ruangan tersebut juga sudah diriset oleh Rosan Bosch, tipe ruangnya antara lain adalah sebagai berikut.
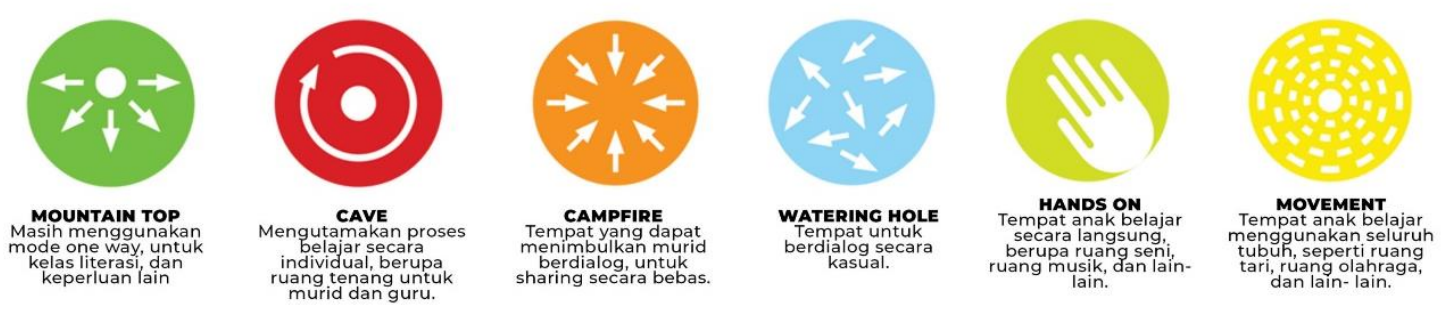

Gambar 2. Tipe Ruangan

Sumber: Rosan Bosch, 2012

Masing-masing konsep ruang ditujukan untuk fungsi yang mendukung kegiatan belajar mengajar, contoh ketika guru sedang melakukan kelas literasi dapat menggunakan kelas dengan tema campfire atau watering hole sehingga akan memunculkan dinamika berdialog yang dinamis antara murid dengan guru.

Program ruang sekolah memiliki komposisi ruang yang bervariasi sesuai dengan visi dan misi sekolah tersebut. Pada dasarnya ada 4 tipe ruang belajar, yaitu formal, informal, pendukung, dan ruang workshop, yang didalamnya memiliki stereotype masing- masing. Tren sekolah di Jakarta masih banyak yang menggunakan tipe traditional classroom sedangkan masih banyak tipe yang bisa digunakan untuk memicu kreatifitas dari anak tersebut.

Metode survey juga digunakan agar pada saat perancangan ada aspek- aspek seperti pencahayaan, sirkulasi kendaraan, sirkulasi pengunjung, program ruang, dan lain- lain dapat sesuai dengan keadaan sekitar, setelah melakukan survey maka semua data yang didapat dianalisa secara makro dan mikro sehingga mendapat sebuah sintesis. 


\section{ANHLIFES MAKinO}

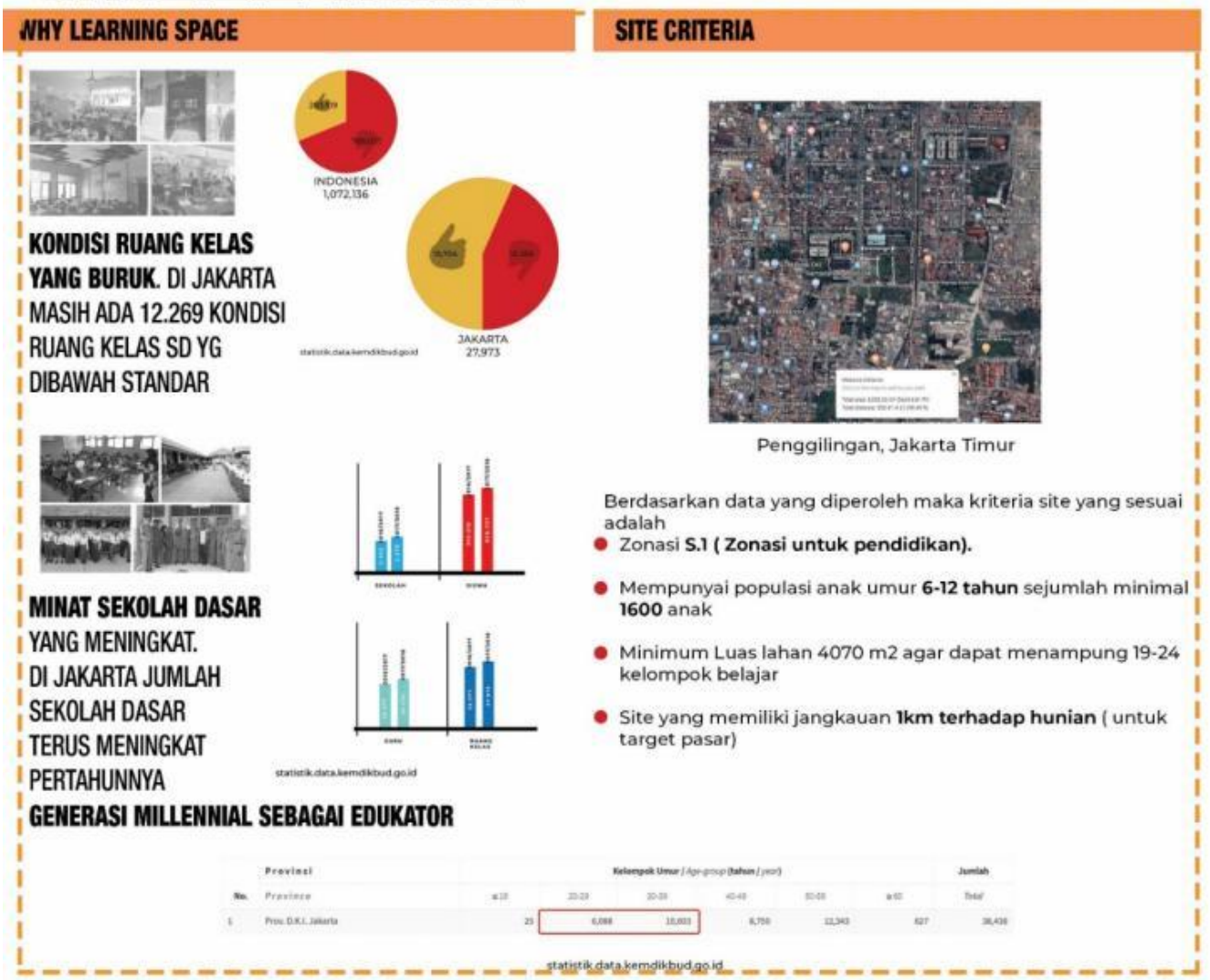

Gambar 3. Analisis Makro

Sumber: Penulis, 2019

Analisis makro dilakukan sehingga menemukan sebuah permasalahan, yaitu mengenai kondisi sekolah dasar di Indonesia, lalu analisa pemilihan lokasi dilakukan berdasarkan kriteria tapak yang sesuai sehingga dipilih tapak yang memenuhi semua kriteria yang ada, yaitu di Kelurahan Penggilingan, Kecamatan Cakung, Kota Jakarta Timur. Peraturan lahan termasuk dalam satu aspek penting dalam pemilihan lahan, oleh karena itu lahan yang terpilih harus memiliki zonasi S.1 (zonasi pendidikan). Analisa Hunian dan Sekolah Dasar sekitar juga dilakukan untuk mencari target pengguna. Luasan minimum lahan untuk sekolah kapasitas 1924 kelompok belajar adalah $4070 \mathrm{~m}^{2}$ agar ruang gerak murid dan pengajar dapat lebih leluasa. Serta desain ruang terbuka untuk murid juga diperlukan agar terjadi dinamika belajar di luar ruangan.

Kawasan yang dipilih terletak dalam daerah perumahan, dan memiliki koneksi langsung dengan RPTRA Pulo Indah, yang memiliki aktivitas dinamis seperti kegiatan masyarakat dalam organisasi yang mendidik karakter seorang anak, hingga memenuhi fasilitas bermain seperti sepak bola dan permainan luar ruangan lainnya. Oleh karena itu konektifitas antara RPTRA dan fasilitas belajar akan diperhatikan dalam mendesain. 

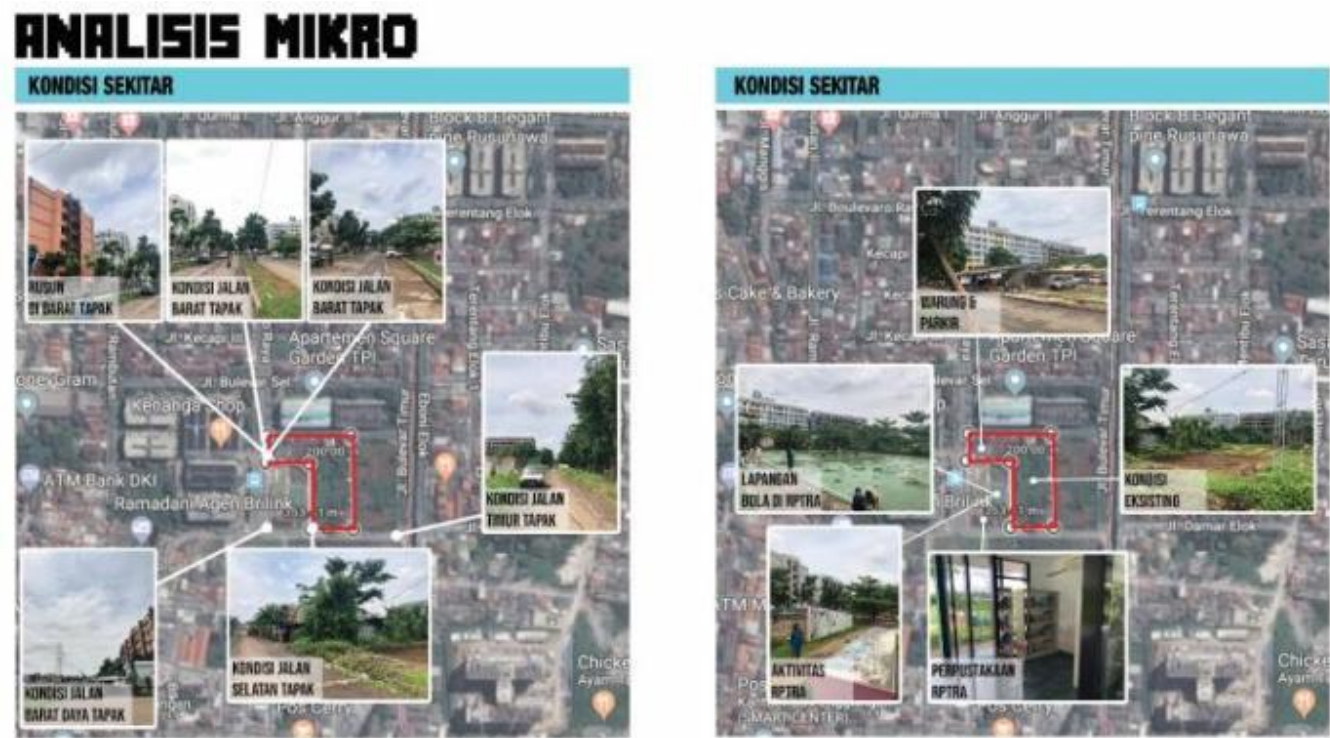

Gambar 4. Analisis Mikro

Sumber: Penulis, 2019

Analisis mikro yang dilakukan adalah pengamatan kondisi sekitar, mulai dari kondisi jalan, fasilitas sekitar, hingga wawancara penduduk mengenai banjir, fasilitas yang dibutuhkan, dan lain-lain. Sintesis yang didapat dimasukan kedalam skema desain yang menghasilkan sebuah gubahan massa serta prinsip- prinsip desain yang dapat bermanfaat dalam bangunan.

\section{DISKUSI DAN HASIL}

Hasil dari penelitian yang dilakukan maka menghasilkan sebuah Future Learning Space dengan konsep ruang belajar yang lebih bervariatif.

\section{DESIGN SCHEME}

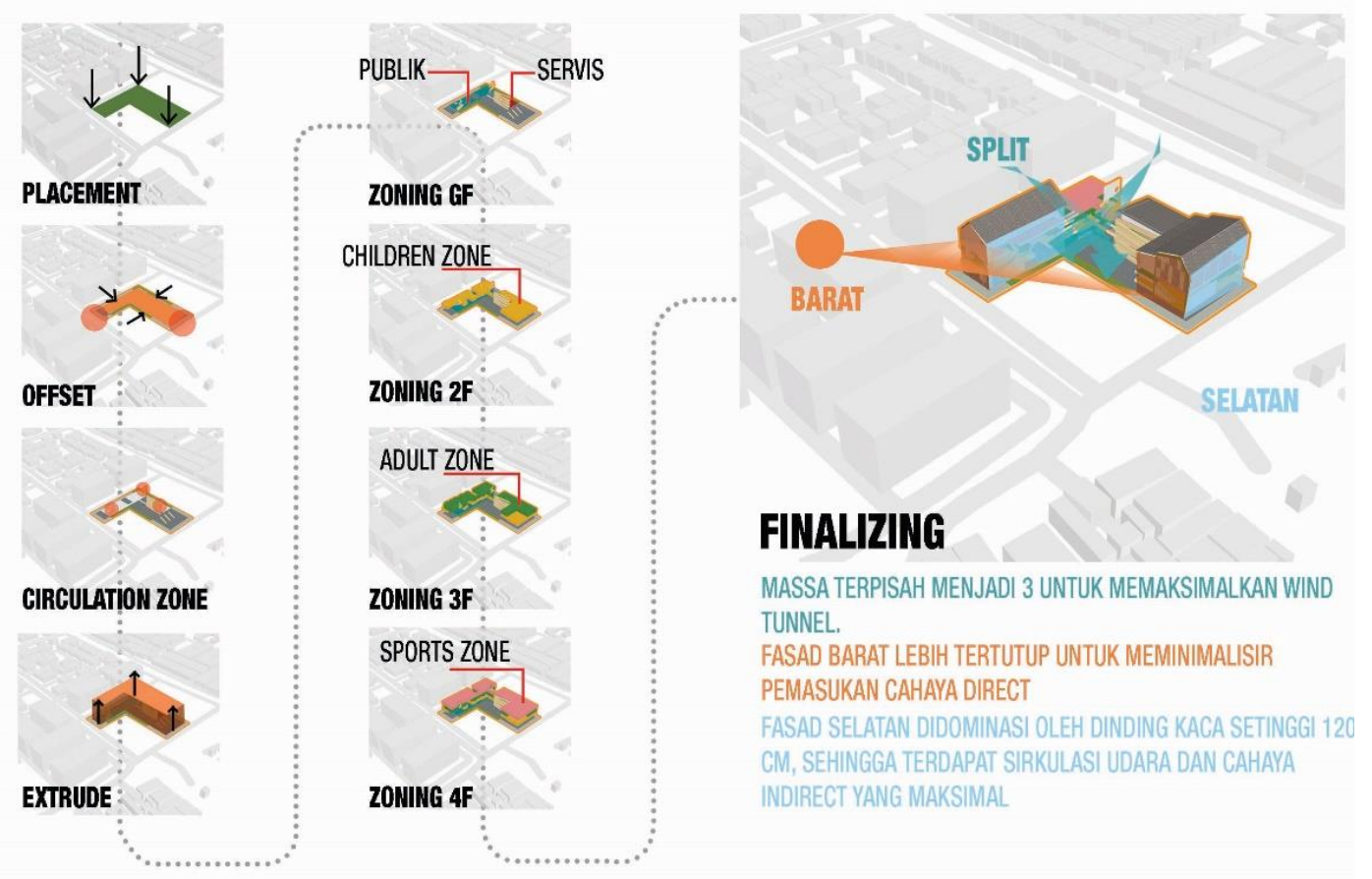

Gambar 5. Skema Desain

Sumber: Penulis, 2019 
Sintesis dari beberapa metode yang dipakai, seperti metode Pattern Language, metode survey menjadi terapan dalam skema desain yang ada. Metode Pattern Language menjadi beberapa tipe kelas yang disesuaikan dengan pola kegiatan belajar mengajar dari generasi milenial. Terbagi menjadi 4 ruang yaitu ruang kelas formal, ruang kelas informal, ruang workshop, dan ruang pendukung.

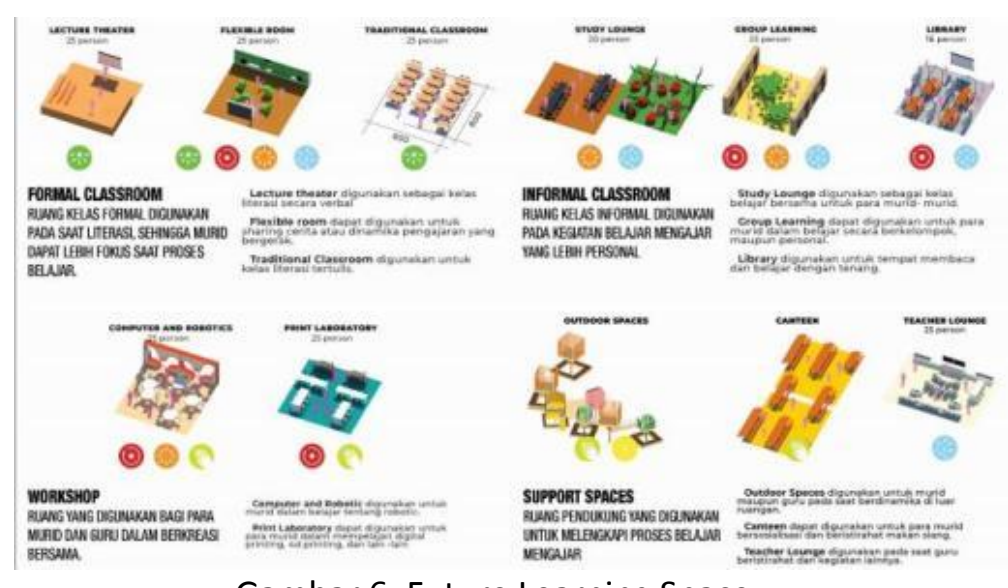

Gambar 6. Future Learning Space

Sumber: Dokumen Penulis, 2019

Kondisi ruang kelas yang ideal di abad ke 21 ini adalah ruang kelas yang fleksibel, dan memiliki desain yang personal, semisal di masing- masing ruang memiliki fungsinya tersendiri, sehingga pengguna bisa memilih ruang yang mana dalam melakukan kegiatan. Suasana ruang yang ingin diciptakan dalam fasilitas ini adalah suasana yang menyenangkan, yaitu dengan memberi warna- warna dinamis di bagian area bermain, dan area belajar yang terkait dengan anak- anak, sedangkan area lebih dewasa lebih di dominasi dengan material kayu dan warna putih, untuk menimbulkan suasana yang nyaman dalam beraktifitas. Fasad bangunan diambil dari lokalitas atap sekitar yang berbentuk pelana, serta penambahan geometris dasar seperti lingkaran dan kotak untuk mendekorasi fasad yang familiar bagi anak.

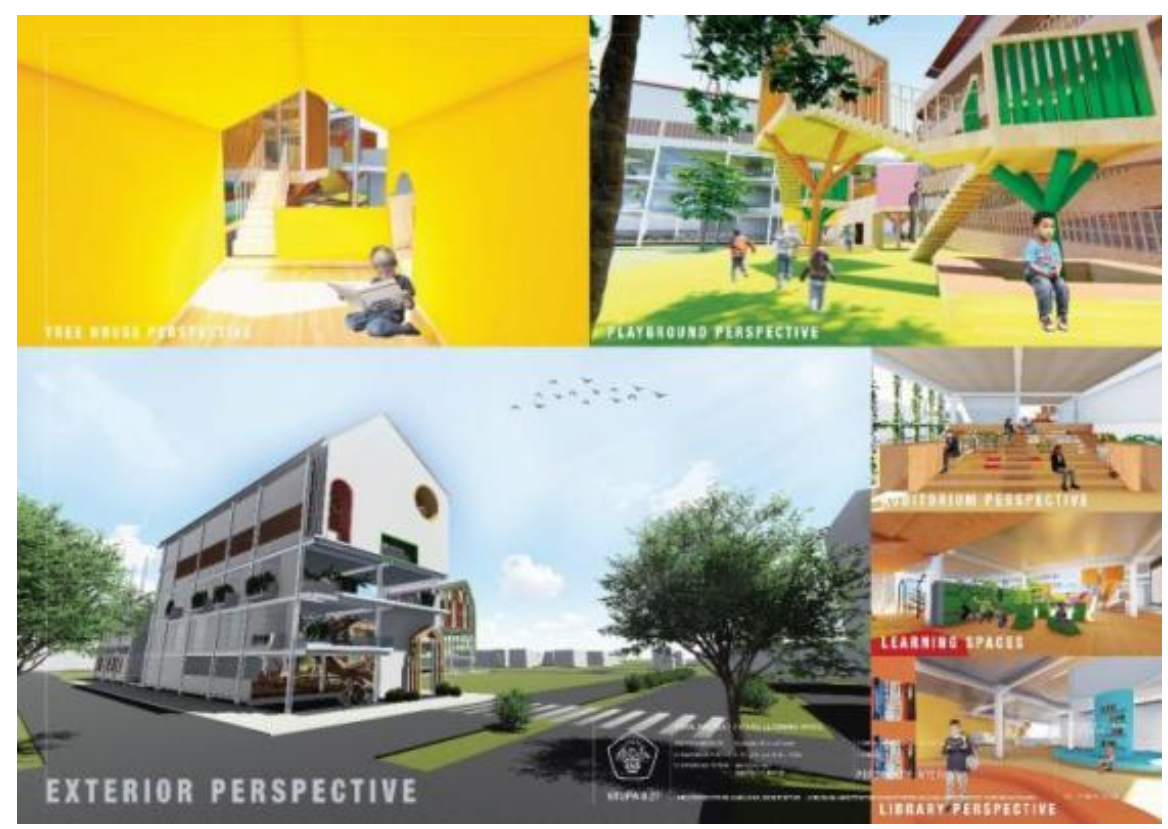

Gambar 7. Konsep Ruang Sumber: Penulis, 2019 
Fungsi ruang yang fleksible akan menjadi solusi dalam paradigma sekolah/ ruang belajar yang sesuai di abad ke 21 agar tetap dapat menyesuaikan jaman. Lantai dasar diisi dengan program pendukung dan area servis, serta adanya konektifitas terhadap RPTRA Pulo Indah menjadi aspek penting dalam perancangan ini.

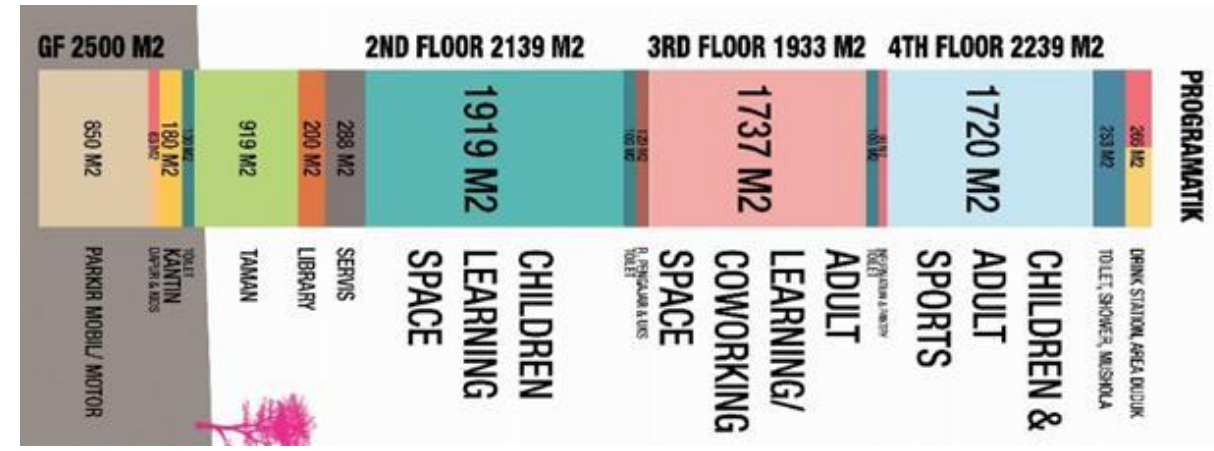

Gambar 11. Program Ruang

Sumber: Penulis, 2019

Program ruang utama terdiri dari fasilitas belajar untuk anak- anak dan remaja maupun dewasa seluas $2139 \mathrm{~m}^{2}$ dan $1933 \mathrm{~m}^{2}$, sedangkan untuk menampung minat olahraga warga sekitar, area olah raga menjadi program pendukung di bangunan ini seluas $2239 \mathrm{~m}^{2}$. Seiring berkembangnya jaman maka pendidikan serta fasilitasnya juga harus mengikuti, oleh karena itu suatu bangunan harus bisa mengikuti perkembangan jaman tersebut.

\section{KESIMPULAN DAN SARAN}

Kesimpulan dari hasil riset mengenai bangunan sekolah dasar konvensional yang sudah tidak relevan lagi di abad ke 21 ini adalah sebuah ruang belajar yang dapat mencakup semua kalangan umur serta sebuah sistem dimana penggunaan yang lebih fleksibel, dan desain yang lebih personal dan variatif, bangunan ini akan mewadahi acara dan kegiatan warga sekitar, sehingga lingkungan menjadi semakin hidup. Studi ini tentunya belum sempurna dan masih memiliki kekurangan, hendaknya bagi penulis maupun pembaca masih terus melakukan studi lebih lanjut.

\section{REFERENSI}

Alexander, C. (1977). A Pattern Language. New York: Oxford University Press.

Archdaily. (2016). Co-working utopic_US Conde de Casal / Izaskun Chinchilla Architects. Retrieved April 22, 2019, from Archdaily: https://www.archdaily.com/794909/co-workingutopic-us-conde-de-casal-izaskun-chinchilla-architects

Archdaily. (2017). School of Alfa Omega / RAW Architecture. Retrieved April 23, 2019, from Archdaily: https://www.archdaily.com/873535/school-of-alfa-omega-raw-architecture

Archdaily. (2017). Tezuka Architects' Fuji Kindergarten Wins 2017 Moriyama RAIC International Prize. Retrieved April 23, 2019, from Archdaily: https://www.archdaily.com/880027/tezukaarchitects-fuji-kindergarten-wins-2017-moriyama-raic-international-prize

Bosch, R. (2012). Vittra Telefonplan / Rosan Bosch. Retrieved April 22, 2019, from https://www.archdaily.com/202358/vittra-telefonplan-rosan-bosch

Branigan-Pipe, Z. (2016). Edtecg \& Design, Promising Practices. Retrieved April 22, 2019, from Ed Tech Commons: http://edtech.ucdavis.edu/getting-started/10-practices/

Communities, S. o. (2012). Curriculum planning and programming. Retrieved April 23, 2019, from

Weebly: http://wpghstheaustraliancurriulum.weebly.com/uploads/1/9/0/3/19034003/curriculumpl anningandprogramming.pdf 
Fahmi, A. N. (2017). Pembelajaran Abad 21 dan Pembelajaran Tematik Integratif. Retrieved a b, 2019, from Universitas Negeri Yogyakarta: http://aidanurf.blogs.uny.ac.id/wpcontent/uploads/sites/15442/2017/10/PEMBELAJARAN-ABAD-21-DAN-PEMBELAJARANTEMATIK-INTEGRATIF-PADA-SEKOLAH-DASAR.pdf

Haerulloh, A. (2014). Holland Inlandsche School. Retrieved a b, 2019, from https://www.academia.edu/31889257/Hollandsch_Inlandsche_School(his)

Haerulloh, A. (2014). Holland Inlandsche School. Retrieved April 24, 2019, from https://www.academia.edu/31889257/Hollandsch_Inlandsche_School(his)

Harususilo, Y. E. (2018). Guru SD Dituntut Lebih Kreatif. Retrieved April 25, 2019, from Kompas: https://edukasi.kompas.com/read/2018/08/06/21180921/guru-sd-dituntut-lebih-kreatif

History, C. (2011). Organisasi Taman Siswa. Retrieved April 22, 2019, from blogger: http://blog-chiex.blogspot.com/2011/08/organisasi-taman-siswa.html

Imaginables. (2016). Guest Blog: Future Learning Spaces. Retrieved April 23, 2019, from Print Lab: https://weareprintlab.com/index.php?p=blog/future-learning-spaces

Kim, D. (2017). Vertical School: A New Typology for the City. Retrieved April 24, 2019, from Research Work Archieve: https://digital.lib.washington.edu/researchworks/handle/1773/40783

Mundy, B. (2012, April 23). the Millennial School ; A Theoretical Basis fir Curriculum Design in a Time of Educational ' Transgression'. 19.

Neira, J. (2019). AEI colorizes daniel bonilla arquitectos-designed anglo colombiano school in bogotá. Retrieved April 23, 2019, from Designboom: https://www.designboom.com/architecture/daniel-bonilla-arquitectos-colegio-anglocolombiano-bogota-08-18-2016/

Teachers, B. (2018). Are Flexible Learning Spaces the Future of Education? Retrieved April 23, 2019, from Bored Teachers : https://www.boredteachers.com/trending/flexible-learningspaces-future-of-education

The School of Art, D. a. (2011). Future Learning Spaces. Designs of E- Learning.

Timur, B. J. (2017). Jakarta TImur Dalam Angka 2017. Retrieved April 23, 2019, from BPS: https://jaktimkota.bps.go.id

Timur, B. J. (2018). Cakung Dalam Angka 2018. Retrieved April 23, 2019, from BPS: https://jaktimkota.bps.go.id

Todd, R. (1999). Design and Technology Yields a New Paradigm for Elementary Schooling. Retrieved a b, 2019, from Scholar: https://scholar.lib.vt.edu/ejournals/JOTS/Summer-Fall1999/PDF/Todd.pdf 
